INJURY CLASSIC

\section{Editor's comment}

The Classic by de Haven is more important than readers may realize. That is why I asked Flaura Winston, whose background in engineering and medicine is so unusual, to introduce it. Together with my gentle encouragement, I hope readers will fully appreciate de Haven's remarkable contribution. Three aspects of his paper are compelling. First, it is based on simple observations and thus serves as a wonderful example of how important these can be. Beginning with this small series of case studies, by applying the inductive approach, de Haven formulated a general theory of prevention. In essence that theory says that the basic laws of physics operate as well in human injury as in other domains. Second, the application of these laws about how force is distributed or absorbed to reduce damage, later elaborated on by Haddon and others, is the basis for most of the most effective injury prevention measures so popular today (harnesses, seat belts, helmets, playground surfaces, etc). Third, de Haven's work was, indeed, the birth of a science. Having laid a solid empirical and theoretical foundation, the next concrete steps were taken by Colonel Stapp (whose death is noted elsewhere in this issue). Stapp began testing the force distribution theories by dynamic sled testing. We will publish some of his findings in a later Classic. The bottom line is: Hugh de Haven was a genuine pioneer and this paper includes many messages that are important to anyone working in injury prevention today. In a later paper, de Haven wrote: “... people knew more about protecting eggs in transit than they did about protecting human heads" and with respect to this issue's Classic, he added: "They [the cases] did more to support my theories about crash injuries and crash survival than all the words in the dictionary. Read and enjoy.

\section{The beginning of injury science}

"Injuries are not accidents". This simple statement has become the mantra of injury control professionals. When did the realization begin that crashes and their resultant injuries were not inevitable but rather were predictable and, therefore, preventable events? In 1919, Hugh De Haven ruptured his liver, pancreas, and gall bladder in an airplane crash as a cadet in the Royal Flying Corps. During his convalescence, he began to question the inevitability of injury as a result of aviation crashes. Thus dawned the field of crash investigation and injury science. When he began presenting the findings of his research, he encountered the resistance and inertia that many of us still experience today: his commanding officer preferred to attribute escapes from injury to the "Jesus factor" and pathology to the "luck of the game". But Hugh De Haven persisted and his commitment to applying a scientific approach to injury led to the acceptance of safety belts as protective devices. "Mechanical analysis of survival in falls from heights of fifty to one hundred and fifty feet" provides one of the earliest examples of injury science. The results of this research continue to be relevant today.

FLAURA KOPLIN WINSTON

Director of TraumaLink,

Interdisciplinary Pediatric Injury Control,

Research Center at the Children's Hospital of Philadelphia and the

University of Pennsylvania,

34th Street and Civic Center Boulevard 2426,

Philadelphia, PA 19104, USA
This is the latest paper in a series of Injury Classics. Our goal is to reprint one or two such papers in each issue to introduce newcomers to these old, often quoted, and important contributions. As many are difficult to find, it should help all of us to have a copy at hand. Your suggestions about future articles are welcome. Write to the editor with details of your favourite, most quoted paper.

\title{
Mechanical analysis of survival in falls from heights of fifty to one hundred and fifty feet ${ }^{\star}$
}

\author{
Hugh De Haven
}

During the interval of velocity change in aircraft and automobile accidents many typical crash injuries are caused by structures and objects which can be altered in placement or design so as to modify the large number of severe and constantly recurring patterns of injury in these accidents. In order conscientiously to approach some of the engineering problems encountered in reduction of the potential injury hazards of windshield structures, seats, instrument panels,

\footnotetext{
Research Associate, Department of Physiology, Cornell University, Medical College, New York

This paper first appeared in War Medicine (1942;2:586-96) and is reproduced with permission. Copyright 1942 by the American Medical Association.
}

${ }^{\star} \mathrm{My}$ interest in the mechanics of injury and safety design dates from experiences in the Royal Air Force during the last war. Observations made at that time, during investigation of air crashes, gave strong indication that many of the traumatic results of aircraft and automobile accidents could be avoided. Structures and objects, by placement and design intructures and objects, by placement and design, created an inevitable expectance of injury in even minor accidents Occasionally, however, accidents apparently having every fatal characteristic would occur without causing physical injury. Detalled evidence of apparently miraculous survival in the instances of free fall described here, indicates the strength of the body under conditions of extreme force closely paralleling those encountered in many severe automobile and aircraft accidents. safety belts, etc, it was necessary to have some understanding of the limits of mechanical strength of the human body.

The objective in studying the physiologic results of rapid deceleration in the following instances of extraordinary survival-after free fall and impact with relatively solid structures-was to establish a working knowledge of the force and tolerance limits of the body. On the basis of these data certain engineering improvements can be considered for aircraft and automotive design.

Loss of pilots through injury due to the increased landing speeds of military planes has become more and more frequent; this loss and the ever present toll by accident in the automotive field are matters of grave national concern. Injuries in these fields are mechanical results stemming from localized pressures induced by force and applied to the body 
through the medium of structure. It is an axiom in the mechanical arts that modification of cause will change results, but the nature and the degree of structural alteration to modify injury to human beings effectively depend on the reactions of the body to abrupt pressure and its distribution. The strength of human anatomic structure and its tolerance of pressure increase are centrally important elements in any proposed increase of safety factors through engineering effort.

Obviously, if the body could tolerate pressure within only narrow limits, few improvements would be worth consideration, since the force and resulting pressure of a severe crash are at best formidable. Evidence, on the other hand, that the body can tolerate the force of an extreme crash-without injury-would indicate that (1) extreme force within limits can be harmless to the body; (2) structural environment is the dominant cause of injury; (3) mechanical structure, at present responsible for recurring injury, can be altered to eliminate or greatly modify many causes and results of mechanical injury, and (4) the greater the evidence of body tolerance of force and pressure, the wider the possibility for considering engineering improvements.

Evidence of the extreme limits at which the body can tolerate force cannot be obtained in laboratory tests for obvious reasons, nor can it be gained satisfactorily from most aircraft and automobile accidents, because the variables of speed and angle are difficult to appraise. Estimation of the exact speed of a crash is difficult under most conditions. Also relative movements during structural demolition generally make it impossible to know the position of the body at the time the injuries were sustained and whether the head or some other injured part overtook the structure before it came to a stop or after it had stopped. In these circumstances, the speed, deceleration, impact and force of the body and their relation to the structure can seldom be fixed.

With the thought of overcoming many of these difficulties and in order to observe physiologic reactions to force under more simple conditions, a study of cases of free fall was undertaken. In several of the cases outlined here speed of fall, striking position, deceleration and relation of resultant injuries to structure could be determined with great precision. Other cases are included because of some specific interest or because they are relevant to the cases in which the evidence is clear.

The material is presented with the hope that additional instances of force survival may be closely observed and recorded in order to further an understanding of the strength of the body and the type of structure, position, etc, contributing to force survival.

It is, of course, obvious that speed, or height of fall, is not in itself injurious. Also a moderate change of velocity, such as occurs after a 10 story fall into a fire net or onto an awning need not result in injury, but a high rate of change of velocity, such as occurs after a 10 story fall onto concrete, is another matter. Between these two extremes lies important evidence of physiologic force tolerance.

In using expression "free fall" a fall free of any obstruction other than that encountered at its termination is implied.

The word deceleration and its derivative decelerative are used in preference to negative acceleration, etc; "velocity at contact", is preferred to "impact velocity".

The force of gravity - denoted by the symbol $g$-is used as a measure of the force of a positive or a negative acceleration.

A deceleration exerting a force 150 times the normal pull of gravity on a body will increase its normal weight 150 times during the time this increase of force acts. Thus, a force of 150 g acting on a man normally weighing 150 pounds $(68 \mathrm{~kg})$ would increase his apparent weight to 22500 pounds (10 $200 \mathrm{~kg}$ ) during the force interval. This increase of force-and weight - would be distributed over, or applied to, his body as pressure in areas of contact dictated by resisting structure.

The velocities reached in the following cases of free fall are estimated from the acceleration equation $\mathrm{v}=\sqrt{2 \mathrm{gs}}$, in which the falling object is accelerated by the force of gravity in a vacuum - $v$ being the velocity, $g$ the value of gravity in the acceleration (32 feet $[976 \mathrm{~cm}]$ per second per second) and $s$ the distance fallen.

Deductions in velocity made on account of the resistance of the air are rather arbitrary and are estimated on the basis of weight, clothing worn and whether the body was observed to be falling head first flat or with a tumbling motion. The higher distances of fall are based on an Air Corps technical report. ${ }^{1}$

The estimated forces of deceleration are made from an inversion of the equation for acceleration, $\mathrm{v}^{2}=2 \mathrm{gs}$, in which $s$ equals the distance in feet through which a known velocity is decelerated. The resultant expression of decelerative force in pounds must be divided by the force of gravity factor (32 feet per second per second) to give the increase times normal gravity.

Minor contusions and lacerations have been omitted in referring to sustained injuries unless they were of special significance.

\section{Report of eight cases}

CASE 1

A woman aged 42, 5 feet 2 inches $(157 \mathrm{~cm})$ tall and weighing 125 pounds (57 kg), jumped from a sixth floor and fell 55 feet (17 meters) onto fairly well packed earth in a garden plot, landing on the left side and back.

Deceleration and acceleration of gravity - The deceleration distance was about 4 inches $(10 \mathrm{~cm})$ as indicated by marks of the body in the earth. The velocity at contact was 54 feet (17 meters) per second (37 miles [60 km] per hour), and the average gravity increase, $140 \mathrm{~g}$.

Injuries - There was no evidence of material injuries or shock. Examination of a sample of spinal fluid showed it to be clear and colorless; 
there were no red cells in the urine. There was no loss of consciousness or abdominal tenderness.

Comment-The superintendent of the building reached the victim immediately after she struck the ground. She raised herself on her left elbow and remarked: "Six stories and not hurt".

CASE 2

A woman aged 27,5 feet 3 inches $(160 \mathrm{~cm})$ tall and weighing 120 pounds ( $54 \mathrm{~kg}$ ) jumped from a seventh floor window and fell 66 feet $(20$ meters) onto a wooden roof, landing head first with progressive contact of the shoulders and the back.

Deceleration and acceleration of gravity - This woman broke through a roof of $3 / 4$ inch $(2 \mathrm{~cm})$ pine boards which were supported on 6 by 2 inch $(15$ by $5 \mathrm{~cm})$ beams 16 inches $(41 \mathrm{~cm})$ apart and landed lightly on the ceiling below. Velocity at contact was 60 feet ( 18 meters) per second (40 miles [64 km] per hour). The average gravity increase was unknown. A hole approximately 16 by 16.5 inches ( 41 by 42 $\mathrm{cm}$ ) was sheared in the roof by the force of the fall. Three of the 6 by 2 inch beams were broken.

Injuries-The scalp was lacerated (occiput), but there was no evidence of other head injuries. The victim suffered abrasions over the dorsal portion of the spine and an oblique intra-articular fracture of the sixth cervical vertebra. There was some spasticity of the abdominal muscles on the right side. Urinalysis yielded normal results. There was evidence of mild shock.

Comment-The fall was first known to have occurred when the woman appeared at an attic door and asked for assistance. She sat up in bed at the hospital later in the day. It is difficult to reconcile the structural damage to the beams with the absence of greater bodily injury in this case.

Another case in which injury occurred under similar circumstances but in which survival was only temporary is summarized as follows:

A man fell 121 feet (37 meters), landing in a supine position on a wooden roof after having jumped from a 14th floor. In this case the roof was broken in at one point to a depth of 8 inches $(20 \mathrm{~cm})$, but this point was not directly under the area of force. The average force was undoubtedly in excess of $200 \mathrm{~g}$. The victim walked away from the spot where he landed. His right arm had struck a 12 by 2 inch ( 30 by $5 \mathrm{~cm}$ ) beam and stopped abruptly; the torso had continued in movement, with a resultant tearing action in the shoulder area. There were other injuries. Death was attributed to severance of brachial arteries, hemorrhage and shock. The circumstances in this case are somewhat similar to those in case 2 , just described, there being no evidence of loss of consciousness or head injury.

CASE 3

A woman aged 36,5 feet 4 inches $(163 \mathrm{~cm})$ tall and weighing an estimated 115 pounds (52 $\mathrm{kg}$ ), jumped from an eighth floor and fell 72 feet (22 meters) onto a fence, face downward.

Deceleration and acceleration of gravity-The distance of the deceleration could not be estimated. Velocity at contact was 65 feet $(20$ meters) per second (44 miles [70 km] per hour) with minor gravity increase.

Injuries - There was no evidence of material injury.

Comment-The victim was seen during the fall and landed "jack-knifed" over the fence, which was constructed of wood and wire. The fence was broken down part way, and the victim tumbled to the ground. She immediately picked herself up and walked to a nearby clinic for first aid. In this case, chief interest is centered on the patient's having struck a 1 by 4 inch $(2.5$ by $10 \mathrm{~cm}$ ) board, "edge up", at the top of the fence at 44 miles per hour, without essential injury to chest or abdomen.

CASE 4

A woman aged 30,5 feet 6 inches $(168 \mathrm{~cm})$ tall and weighing 122 pounds (55 kg), jumped from a ninth floor, falling 74 feet (23 meters) onto an iron bar, metal screens, a skylight of wired glass and a metal lath ceiling; she landed face downward, prone.

Deceleration and acceleration of gravity-The decelerative distance must be computed in three stages, combined and confused, totaling 45 inches $(114 \mathrm{~cm})$. The velocity at contact was 66 feet (20 meters) per second (45 miles [72 $\mathrm{km}$ ] per hour). The average gravity increase was undetermined but was minor except in impact areas.

Injuries - This woman had minor patterned contusions and an $\mathrm{H}$-shaped laceration on the forehead from the screen wires. All other injuries were minor except in the thoracic area, where there was marked tenderness of the upper ribs on the right side near the anterior axillary line, with slight crepitus. There were slight rigidity of the left side of the abdomen, contusions of the right side of the chest and severe localized ecchymosis $6 \mathrm{~cm}$ above the costal margin. Roentgen examination showed fractures of the fourth, the fifth, and the sixth rib on the right side. There had been no loss of consciousness and only moderate shock.

Comment - The fall was witnessed, and there is little doubt that the victim struck a heavy iron bar at the termination of the fall, while speed was substantially 45 miles per hour. The contact was in the thoracic area, with the resultant injury just described. The bar was T-shaped structural iron, 1.5 by 1.5 inches ( 4 by $4 \mathrm{~cm}), 6$ feet 6 inches $(198 \mathrm{~cm})$ long and weighing 13.5 pounds ( $6 \mathrm{~kg}$ ); one end of it was embedded in masonry. The stem of the $\mathrm{T}$ was up. There was a fresh, localized bend in the bar 13 inches $(33 \mathrm{~cm})$ deep. That more severe chest and other injuries were not sustained is remarkable, especially in view of the extraordinary demolition of structural steel and glass resulting from the force of this fall.

The woman immediately sat up, rose to her feet and was helped through an adjacent 
window and given immediate first aid. She was admitted to a hospital and made a rapid, uneventful recovery.

A case in which the conditions of free fall and impact were similar is summarized as follows:

A person fell 100 feet (30 meters) onto a screen with iron supports over a skylight, landing face downward and demolishing these structures. Injuries included fracture of the seventh, the eighth, and the ninth rib on the right side, a right pneumothorax and subcutaneous emphysema; there was moderate shock but no head injuries. At the end of three weeks the right lung was expanded and the patient's temperature was again normal; recovery was uneventful.

CASE 5

A woman aged 21,5 feet and 7 inches $(170 \mathrm{~cm})$ tall and weighing 115 pounds (52 kg) jumped from a 10th story window, falling 93 feet (28 meters) into a garden where the earth had been freshly turned and landing nearly supine on the right side and back, with the occiput striking the soft earth.

Deceleration and acceleration of gravity-The decelerative distance was a maximum of 6 inches $(15 \mathrm{~cm})$, according to the marks in the earth, which varied for different parts of the body. The velocity at contact was 73 feet $(22$ meters) per second (50 miles [80 km] per hour), and the minimum gravity increase was $166 \mathrm{~g}$.

Injuries-This woman fractured a rib on the right side and the right wrist. There was, however, no loss of consciousness and no concussion.

Comment - Several people were standing nearby when this patient struck the ground. She talked almost immediately and wanted to arise but was not permitted to do so. She entered the hospital, where she remained for 12 days. The earth in the flower bed where she landed had been spaded to a depth of 6 or 7 inches $(15$ to $18 \mathrm{~cm})$. The earth packed hard under the force of this fall, and the gravity increase was estimated to have mounted to more than $200 \mathrm{~g}$ toward the end of the decelerative movement.

CASE 6

A man aged 42 , of unascertained height and weight, fell 108 feet (32 meters) from a 10th story window and landed on the hood and fenders of an automobile, face downward.

Deceleration and acceleration of gravity-The decelerative distance varied from 6 to 12 inches $(15$ to $30 \mathrm{~cm})$ for different parts of the body, and impact due to inertia of the structure was involved. With a velocity at contact of 79 feet (24 meters) per second (52 miles [83 km] per hour) the gravity increases were close to 100 and $200 \mathrm{~g}$ without inertia and other consideration.

Injuries-This man sustained a depressed frontal fracture of the skull, but the immediate cause of this injury was not determined. $\mathrm{He}$ had bounced from the car to the pavement. Head injuries observed in like accidents have occurred as a result of bouncing from a decelerative structure to a hard surface.

Comment-This patient survived and is now in good health. Unfortunately, the medical history of the case is not available, but at the time of the accident the patient was reported to have sustained no loss of consciousness, to have slept well and to have had a good appetite. The force was well distributed except in the area where the fracture occurred.

A case in which the conditions of falling and impact were similar is summarized as follows:

A man fell from the top of a factory building (134 feet [40 meters]), landing face downward on the hood and fenders of a car. The force was not well distributed in the abdominal area. The lower half of the abdomen (below the umbilicus) was strongly supported by the hood of the car; the head and chest struck the fender, which was demolished. There were no material facial injuries and only brief loss of consciousness, with no other indications of head injury from this primary fall. The man bounced from the car to a height of " 2 or 3 feet $(60$ to $90 \mathrm{~cm})$ " and was observed to land head downward on the pavement after a fall of about 5 feet $(152$ $\mathrm{cm})$. There were frontal scalp lacerations at the hair line related to this secondary fall onto the head, and this, in itself, was considered sufficient to cause temporary loss of consciousness. Preliminary roentgen examination showed "a line of decreased density extending upward from the orbital plate close to the coronal suture". The upper portion of the abdomen, ie, between the thorax and the umbilicus, received little or no support during the deceleration of the speed of this fall, and there was severe shearing stress in this region. There was no apparent intrathoracic injury. The patient died 24 hours after the accident, death being attributed to shock. At autopsy no rupture of major internal organs was revealed.

\section{CASE 7}

A man aged 27, 5 feet 7 inches tall and weighing 140 pounds $(64 \mathrm{~kg}$ ), jumped from the roof of a 14 story building, falling 146 feet ( 44 meters) onto the top and rear of the deck of a coupe and landing in a semisupine position.

Deceleration and acceleration of gravity-The decelerative distance varied, the extreme depth of the dent in the car structure being 8 inches $(20 \mathrm{~cm})$-about 5 inches $(13 \mathrm{~cm})$ where the head and shoulders struck. The velocity at contact was 86 feet ( 26 meters) per second (59 miles [94 km] per hour). The gravity increase was not estimated because of the unknown factors of relative movement, inertia of the structure, action of the car springs, etc.

Injuries-The patient sustained numerous fractures as follows: compound, comminuted fracture of the left elbow; impact fracture of the head and the neck of the left humerus; comminuted fracture through the spine of the left scapula; compression fracture of the seventh and the eighth dorsal vertebra, and fracture through the base of the greater tuberosity of the ischium. He suffered moderate shock but was conscious; there were no chest or head injuries. 
During the first week in the hospital the abdomen was distended and the patient vomited, probably evidence of some internal injury. In the second week jaundice developed, but otherwise recovery was uneventful. The man returned to work two months later, when the arm was healed.

Comment-The chain of injuries to elbow, shoulder, scapula, and vertebrae indicates that the left arm was subjected to great force, probably before the body was otherwise well supported. It is conjectured that the left arm struck the lower sill of the rear window before the rest of the body struck and dented the roof structure. The suggestion of internal injury may also be related to this abrupt, localized force, or to the "steamer chair" position in which the general force of the fall was taken.

A case in which the position of the body at the moment of impact was similar is summarized as follows:

A woman, who jumped from a 17 th floor, falling 144 feet (43 meters) in a similar "steamer chair" position, landed on a metal ventilator box 24 inches $(61 \mathrm{~cm})$ wide, 18 inches $(46 \mathrm{~cm})$ high and 10 feet $(300 \mathrm{~cm})$ long. The force of her fall crushed the structure to the depth of 12 to 18 inches (30 to $46 \mathrm{~cm}$ ). Both arms and one leg extended beyond the area of the ventilator, with resultant fractures of both bones of both forearms, the left humerus and extensive injuries to the left foot. She remembers falling and landing. There were no marks on her head or loss of consciousness. She sat up and asked to be taken back to her room. No evidence of abdominal or intrathoracic injury could be determined, and roentgen examination failed to reveal other fractures. The average gravity increase was a minimum of $80 \mathrm{~g}$ and an average of $100 \mathrm{~g}$.

CASE 8

In this case the history has been reconstructed from a paper by Turner, written in $1919^{2}$ :

The victim of this mishap fell from the top of a cliff 320 feet (96 meters) high. The face of the cliff was "perpendicular from top to bottom" except for a slight projection half way down "which can scarcely be called a ledge for it would be quite impossible to obtain a foothold on it". The beach is described as "an ordinary beach with chalk boulders and a little gravel debris". Turner stated: "Some French laborers were at work on the beach at the time and two of them noticed a falling object against the white of the cliff, saw this strike and bounce from the ledge already described, and hardly realized it was a man until he fell on the beach about 50 yards from where they were working".

The occurrence could be classed as survival of two falls of 160 feet ( 48 meters) each, the assumption being that the fall was fully checked about midway at the ledge. There is no certainty that the fall was free in the first phase, as the man may have brushed against the face of the cliff prior to striking the ledge. If one assumed that the fall was free after the man bounced from the ledge and if one deducts 50 per cent from the speed of the first 160 foot fall, because of retarding action, the resultant speed would be 41 feet ( 12 meters) per second as he passed the midway point, equivalent to a fall from 25 feet ( 8 meters) above.

The velocity on striking the beach can therefore be regarded conservatively, as equaling that of a fall from a height of 185 feet (57 meters) -65 miles $(104 \mathrm{~km})$ per hour.

Aside from a large tearing wound of the right knee "where a flap of superficial tissue was torn up on the anterior, external, and posterior aspects of the joint", injuries were largely confined to the scalp where there were "about 10 wounds, four of which extended down to the bone".

There was no apparent fracture of the long bones or intrathoracic or abdominal injury. The flap wound was attributed to striking against the ledge in passing, the scalp wounds to stones on the beach. The head struck some object with sufficient inertia to cause a fissured fracture of the skull, and the patient was unconscious for three days.

"The subsequent progress was remarkably good ..... and the only sign of any intracranial trouble was ..... slight left facial paralysis ..... with inequality of the pupils, the right being the larger. No further symptoms were noticed, and even these cleared up in a week or 10 days".

Turner, in remarking on the comparatively slight nature of the injuries in this case, suggested: "It is just possible that an updraught might have got in beneath the heavy service great coat and exercised sufficient 'parachute' action to considerably break the fall". This, indeed, may have contributed to the result.

The distance of the decelerative action of the beach and the depth of the imprint of the body were not noted. As a decelerative distance of 9 inches $(23 \mathrm{~cm})$ after contact with the beach would limit the gravity increase to $191 \mathrm{~g}$, in view of the other cases in evidence survival can more probably be attributed to the decelerative factor.

\section{Comment}

Seven cases of free fall are presented in which the height of the fall was exactly known and the resultant speed conservatively estimated. In estimating the gravitational increases great difficulties stood in the way of exactness. Even in the falls to earth there was variation of the decelerative distance of the fall for various parts of the body; the hand, for instance, might be stopped in a distance of 2 inches, whereas the hips or head might leave a mark 5 or 6 inches deep. In falls to structure these conditions were also greatly confused. A head striking a fender of a car after a long fall might leave a material dent or distortion, but where the feet struck the fender on the other side there might be only a slight mark.

There can be no doubt that gravity increases occurred greatly in excess of those estimated for the cases reported here. In the case summarized in the comment on case 7 , in which the fall of 144 feet terminated on a metal ventilator, a typical example is provided of 
"yield", or "give", in structure poorly designed for the conditions imposed on it. The metal was light and crumpled easily when first subjected to force, but as it assumed its final flattened form, extreme force was required to crumple or flatten it further. It is probable that its resistance induced a gravity increase greatly exceeding $200 \mathrm{~g}$ as it took its final form.

Since the blood weighs about 12 times the weight of an equal volume of iron under a force of $100 \mathrm{~g}$ and about 25 times the weight of iron under a force of $200 \mathrm{~g}$, it seemed probable when this study was undertaken that some progressive sequence of lesions would occur due to hydraulic action of the blood under these excessive conditions. It was thought that these lesions would in themselves serve as some evidence of the force to which the body had been exposed. Absence of evidence of this kind is attributed to the brevity of the force intervals involved in the cases studied.

As distribution and compensation of pressure play large parts in the defeat of injury, it is significant that a deep sea diver can withstand compensated pressures exceeding 300 pounds $(136 \mathrm{~kg})$ to the square inch on his body without injury. The pressure rise in the cited cases of velocity change was not high, but it was abrupt and was sustained on one side of the body only. Absence of greater injury in the pressure areas or at their edges and larger indication of bursting effect and injury by distortion is noteworthy.

Two of the cases summarized, relate to pure deceleration; two represent extensive structural demolition with survival injuries, and two others relate to striking specific objects with great destructive force and minor injury.

In cases 1 and 5 the falls were to earth, where the deceleration began without great impact and the decelerative distance could be accurately observed by the marks of the body.

In cases 6 and 7 the falls were onto automobiles, where the force of the body demolished mechanical structure without excessive injury to the body. These decelerations included inertia and other factors which made the deceleration uneven and, in parts, extreme.

In case 2 the force of the fall demolished the roof planking and broke three 6 by 2 inch beams, with only one skeletal fracture and little other injury.

In case 3 a wooden fence was demolished by some anterior portion of the chest or abdomen, with trivial injury.

In case 4 a 1.5 by 1.5 inch structural T-shaped iron bar was bent 13 inches by the anterior portion of the chest, without extensive traumatic result. In this case the circumstances closely resemble those in instances in which a pilot is thrown through an instrument panel, bending and breaking tubular bracing structure, with minor facial and thoracic injuries.

The injuries in cases 1 through 7 can be summarized as follows:

1. There was no skull fracture or concussion in case $1,2,3,4,5$, or 7 .

2. Intrathoracic injury was not in evidence in any case.
3. There was no indication of material internal injury in case $1,2,3,4,5$, or 6 .

4. Fracture of the long bones of the arm occurred in 1 case only.

5. There was no fracture of the long bones of the legs in any case.

6. Damage to the rib cage occurred in case 4, in which the localized force was high because of the limited area of contact with the iron bar.

7. Pelvic fracture was lacking in all cases except for the fractured tuberosity in case 7 .

8. The chain of injury in case 7 to the arm, shoulder, scapula, and vertebrae and the cause have already been referred to.

9. One other vertebral injury occurred, in case 2, an injury of position.

Any of the foregoing injuries can be substantially duplicated in a 5 foot $(152 \mathrm{~cm})$ fall. In correlating the aforementioned injuries with those incurred in many aircraft and automobile accidents the direct relation of force to decelerative distance must be constantly considered. A person who escapes in a high speed crash, fatal to many others, owes his life to some decelerative interval and to a favorable distribution of pressure.

It should be borne in mind that the decelerative distance of an airplane, crashing at a speed of 120 miles $(192 \mathrm{~km})$ per hour is seldom limited to a distance of 4 feet $(122 \mathrm{~cm})$ except in the demolished frontal areas. If the pilot's position is to the rear, 4 feet of deceleration will limit the force at this point to an average of $121 \mathrm{~g}$. The average 50 miles $(80 \mathrm{~km})$ per hour crash of an automobile usually involves a stopping distance greater than 2 feet $(60 \mathrm{~cm})$ and the passengers could be limited to a gravity increase of approximately $44 \mathrm{~g}$ if they were in contact with or otherwise related to the structure. A slip on the street, however, where the head strikes the hard pavement may induce a gravity increase exceeding $300 \mathrm{~g}$ because of the small decelerative factor involved. Here the force is highly localized both in time and in area, and the results are often fatal. It is significant that crash survival without injuries in aircraft and automobiles occurs under conditions which are seemingly extreme and that fatal injuries are often sustained under moderate and controllable circumstances.

The mechanical causes of injury and the engineering possibilities for protection are beyond the scope of this paper. It is sufficient to state that the cases reported or summarized here present physiologic evidence of well known mechanical and physical laws; that the primary causes of injury-impact and localization of force-are defeated when distributed in distance (time) and area (space), and that the brevity of the force interval and compensation of pressure can yield amazing results accidentally or when converted to safety purposes through engineering.

The fact that these survivals occurred when the necessary factors were accidentally contributed is strong evidence of the large increase in safety which can be provided by design. 


\section{Conclusions}

The human body can tolerate and expend a force of 200 times the force of gravity for brief intervals during which the force acts in transverse relation to the long axis of the body.

It is reasonable to assume that structural provisions to reduce impact and distribute pressure can enhance survival and modify injury within wide limits in aircraft and automobile accidents.

1 Determination of the rates of descent of a falling man and of a parachute test weight. Air Corps Technical Report, No 2916. Air Corps Inform Circ Nov 24, 1928, Vol 7, No 628.

2 Turner P. A fall from a cliff three hundred and twenty feet high without fatal injuries. Guy's Hosp Gaz 1919;33: 27-80.

\section{Blame that also falls on parents}

No one could fail to be sorry for David Davies who was seriously injured when he fell through a skylight on the roof of his school. Whether Liverpool ratepayers should fork out compensation is another matter. It is natural enough for the boy's mother to blame the school because teachers had not warned him that if he climbed on the roof, stamped on the skylight and fell through, it was a $20 \mathrm{ft}$ drop and he might be hurt. What I find amazing is that a judge should conclude that the boy was only $60 \%$ responsible for the accident and the school $40 \%$, opening the way to compensation. The compensation is a self destructive madness which benefits no-one-except the lawyers and judges whose jobs depend on it (adapted from the Mail on Sunday (London), November 1999).

Death associated with soda syphon bulb

A 10 year old boy has died as the result of an exploding soda syphon bulb. A coronial inquest has established that the boy had taped three soda bulbs together with plastic insulation tape and then placed them inside aluminium foil along with strips of toy pistol caps. This was put in a fire and exploded. A fragment of the soda syphon entered the boy's forehead and, although the cap weighed only three grains, the forensic pathologist commented that it had done damage equivalent to a gunshot injury using centrefire ammunition.

It appears the boy may have got the idea from conversations at school after a Scout camp at which there was a demonstration using a soda bulb to propel a handmade "rocket" along a piece of string. The boy's father had purchased a box of 10 bulbs in order that they could repeat the activity and they had done so a number of times.

Soda bulbs are sold in supermarkets in packs of 10 for about $\$ 8.50$ (Aus). There is no restriction on sale to minors. Some packs are labelled with a "compressed gas" green hazard label; all carry a warning in relation to heat, either a warning to avoid temperatures over $50^{\circ} \mathrm{C}$ or to keep the bulbs in a cool place.

Australian Bomb Data Centre reports record 1011 incidents of soda bulbs used as explosive devices reported to police since 1989 but it is generally assumed the actual figure is much higher.

The coroner conducted the case as an open hearing to raise public awareness of the injury risk. She recommended labelling to make purchasers aware of the risk associated with fire and that retailers consider voluntary restrictions on sale to minors (taken from State Coroner Victoria Case No 861/99).

Fatalities register and suicide mapping

Two separate measures will assist in understanding death in Australia.

A new Australian register will document every drug overdose, murder, suicide, and road death in the nation within 48 hours. In (what is thought to be) a world first, details of all fatalities, murders, and suicides will be recorded on a national database. Legal authorities say the system will act as an early warning system across the whole country. Various authorities will be able to have early warning of dangerous products, transport issues, extra strong or adulterated drugs and to take early action. Initial details of each death will be supplied by police officers attending the scene. Full coronial inquiries will then proceed with reports and findings included in the database. The National Centre for Coronial Information at Monash University is already collecting data with the system expected to be fully operational by mid- 2000 . While excellent data have been available in some states for a number of years, in others there has not even been a central coroner's collection. One of the driving forces behind the national system is Victorian State Coroner, Graeme Johnstone, who said that 10 years of work has gone into the program (Herald-Sun (Melbourne) October 1999).

In what is also claimed to be a world first, Sydney researchers have been funded by the National Health and Medical Research Council to produce a map charting self inflicted deaths across the country and matching them with information on depression, socioeconomic status, and a range of other factors (The Age (Melbourne) November 1999). 